\title{
Conceptual Metaphors of "water" in Javanese Proverbs from a Cognitive Linguistic Perspective
}

\author{
Fajria Noviana $^{1 *}$, Akhmad Saifudin ${ }^{2 *}$ \\ ${ }^{1}$ Universitas Diponegoro, Fakultas Ilmu Budaya, Jl. Prof. Soedarto, Semarang, Indonesia \\ ${ }^{2}$ Universitas Dian Nuswantoro, Fakultas Ilmu Budaya, Jl. Imam Bonjol 205, Semarang, Indonesia
}

\begin{abstract}
This paper examines how the Javanese views the concept of water. Water is one of the natural elements whose existence is essential for humans. This study examines Javanese proverbs containing the word "water" or banyu in Javanese through a qualitative paradigm and a cognitive linguistic approach. Data were obtained from the Javanese Proverbs Dictionary by Darmasoetjipta. Proverbs are used as the object of study, considering that proverbs are one of the language products of a culture born based on the experience of human interaction with nature or the world and has been hereditary believed to be one of the guidelines or advice for life. The proverb contains metaphors so that in examining it, this research uses conceptual metaphor theory. Metaphor is not simply a language feature; it is also an embodiment of human nature. Metaphor is an effective cognitive tool to study how the human thinking mechanism is, how humans perceive reality in an image schema, map it in cognition, and express it through language. Based on the data analysis, it was found that water, according to the Javanese, is seen as a conceptualization of ideological values used as guidelines in social behaviour and social relationships.
\end{abstract}

\section{Introduction}

We know that the natural environment is very influential in every aspect of human life, including culture and language. Humans create a culture to adapt to the natural environment around them to survive. Humans who live in an icy environment, for example, will develop tools, ways of life, and others that are following their environment. They will create shoes or footwear, clothes, houses that can help them survive their cold and snowy climate. Indeed, this fact is different from human life in forests, mountains, or beaches. Therefore, we can say that culture is created due to human adaptation to the environment and language, which is part of human culture. Like culture, the existence of language is much influenced by its natural habitat. For example, in Javanese, with a fertile natural environment, tropical climate, plenty of water, and sunshine, plants such as grasses, including rice, can thrive in Javanese soil. The results of the rice plant were then used as the primary food ingredient for Javanese. Thus, the Javanese language created expressions about rice that were more prosperous and

* Corresponding author: fajria.noviana@live.undip.ac.id 
more varied than other areas where the main food ingredient was not rice. In Javanese, we can recognize the terms gabah 'rice grains wrapped in husks (rice husks), 'pari 'a plant that produces rice seeds,' beras/uwos 'rice seeds been peeled,' sega 'cooked rice,' and others. This example is part of the evidence that the environment dramatically influences culture and language.

This paper examines how the natural environment affects culture and language. The study was carried out through language products, namely in proverbs studied with a cognitive linguistic approach to finding out how Javanese human cognition in perceiving the natural environment was then expressed through language representation Javanese way of thinking. The theory used is the conceptual metaphor theory [1], considering that proverbs always contain metaphors, and metaphors are an effective way of looking at human cognitive perspectives. This paper examines a proverb that uses a word that is one of the elements of the natural environment, namely water.

According to Seitel [2], the proverb is "short, traditional, 'out-of-context' statements used to further some social end." Then according to Mieder: "a proverb is a short, generally known sentence of the folk which contains wisdom, truth, morals, and traditional views in a metaphorical, fixed and memorable form and which is handed down from generation to generation" [3]. Norrick also stated that "proverbs are traditional, pithy, often formulaic and/or figurative, fairly stable and generally recognizable units" [4]. Proverbs have been, are, and will always be timeless. Proverbs are condensed, but memorable sayings embody some necessary experience taken as confirmed by many people. Furthermore, proverbs are similar to metaphors, and they are sayings or stories intended to assist learning, either formal learning or informal family or folk learning. Proverbs are also used to sum up life experiences and let the listener draw conclusions by himself and apply them to his behavior in the future. Thus, because the proverb holds deep metaphorical meaning and is integrated into the daily activities and challenges of the peoples, Finnegan [5] argues that proverbs are highly culture and context-dependent and thus cannot be understood outside the cultural context which they are spoken. Proverbs are the gems of wisdom, a mixture of wisdom \& philosophy. It does not argue over a point or explain anything; it just tells us a great truth in the most significant way. They are coined in order to impart practical knowledge to humankind. It is excellent truth with profound thinking and tons of experience. Most proverbs are anonymous. They are confirmed in different contexts and influence us in many ways. Elders sometimes use proverbs to explain phenomena, and thus, it has a significant impact on our minds.

Water is one of the elements of the natural environment, which is the main element in human life [6,7]. Water has functioned as life energy (as intake) and an instrument in human life (washing, cooking, farming, transportation)[8]. The interaction of humans and water gives birth to many experiences for humans [9]. Through this interaction, humans can identify the characteristics of water both from the quality, quantity, movement, and properties inherent in water, which in its development become a representation and comparison for other elements in life. This fact means that water means physical, cultural, and social meaning for human beings, perhaps even extending to other things, such as politics or economics. Facts like this are, of course, essential to be studied in research.

Naicker [10] examines the use of the water domain in Swami Vivekananda's thought in Hinduism. With the data source in the form of a book by Vivekananda entitled The Complete Works of Swami Vivekananda and using a cognitive linguistic approach and conceptual metaphor theory, this study results in its versatility and role in everyday life; Vivekanda uses water to explain his thoughts on Hinduism. Both the concept of divinity, thought, and spirituality. The use of water metaphors in Hinduism is different from Western religions, which mainly use the FAMILY metaphor. This research emphasizes the importance of water in human life, especially for Hindus. Although Hinduism has links with Javanese society in the past, this research cannot represent the Javanese view of the water. Then Ma and Suhardi 
[11] used entity metaphor theory to analyze entity metaphors about water data. The object of this research was the words or phrases that use entity metaphors and connect with water in the sentences of Cerita Rakyat Jawa Timur. This research used the systematic metaphor analysis method to collect and analyze data. They found four kinds of metaphors of the entity models about water and four characters of entity metaphors about water. Those four kinds of metaphorical entity models about water are that obstacle or dangerous thing is water; the vital thing is water; the challenging situation is water, and the mind is water. The characters of entity metaphors about water are that water is hindering and dangerous; water has vitality; water has bearing capacity because water can determine the success or failure of an event, and water is dynamic. The data were taken from conversations in which water was used and its various forms, such as sea, river, lake, and rain. In such data, the concept of water can only be contextual and subjective. It is not a cultural product of a society that the Javanese people have more confidence in over the years, as the proverb has become the data in this study. Our research results in the Javanese views and philosophy of the world are conceptualized into the metaphor of water.

\section{Methods}

This research used a dictionary of Javanese proverbs entitled Kamus Peribahasa Jawa [12] as the data source. It used conceptual metaphor analysis as a qualitative research method to collect and analyze the objects. The objects are the proverbs that contain banyu 'water' in that dictionary. This research method identifies the topic, collects data, systematically analyzes data, synthesizes and reconstructs the metaphorical concept.

Conceptual Metaphor Theory defines conceptual metaphor as understanding one conceptual domain in terms of another conceptual domain. Thus, we draw metaphorical expressions from the source domain, the more concrete sphere, namely banyu 'water', to understand the more abstract knowledge domain from the target domain [13]. This process of understanding meaning can be described as a set of correspondences formed at the conceptual level between the entities in the two domains through cross-domain mappings and metaphorical entailment [14].

In the analysis, we followed two following procedures: first, a lexical-semantic and morphological analysis of the metaphorical expressions in the proverb given, accompanied by a discussion of the properties of the source domain concept, based on Javanese culture's view. Second, we established mapping or correspondences between the philosophical connotations of the designated target domain concept and developed the properties of the source domain concept. This act used a set mainly based on cross-domain mapping and metaphorical entailment.

\section{Result and Discussion}

\subsection{Result}

This research has found nine proverbs that contain water metaphors in the source resources. Based on the data analysis, it was found that water, according to the Javanese, is seen as a conceptualization of siblings, human nature, community, sustenance/valuables, and knowledge. Furthermore, it is discovered that similarities or analogies characterize the metaphorical mappings of "water" in Javanese. Therefore, the metaphorical mappings of "water" are based on the prototypical features of water resulting from people's experience and interaction with water. 


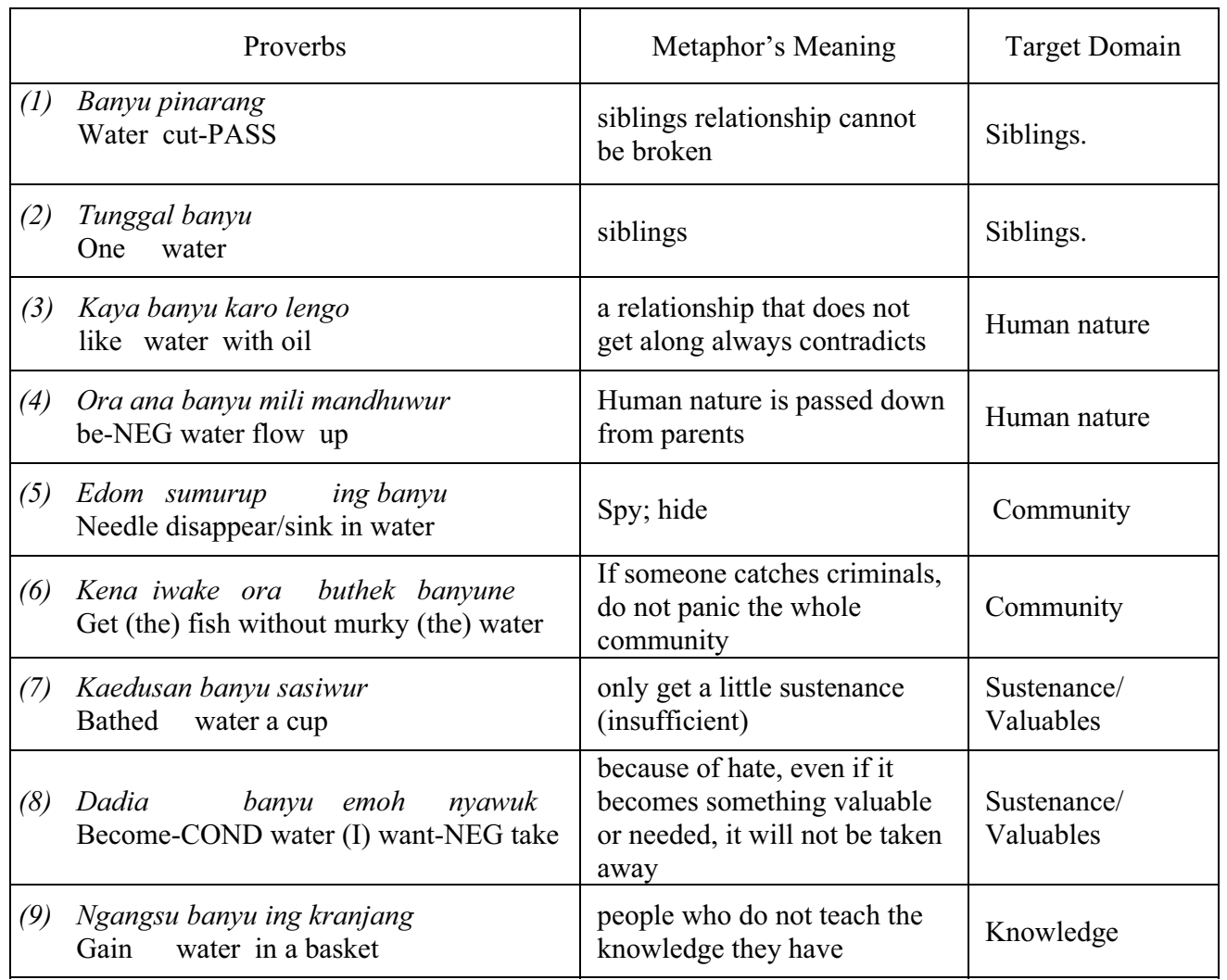

Note:

PASS : Passive voice

NEG : Negation

COND : Conditional mood

\subsection{Discussion}

The Javanese are the largest ethnic group in Indonesia. Most of them live in Central Java and East Java. In the past, most populations of Javanese are farmers, and according to Geertz [15], they are religious people, be they Islam, Hinduism, or believe in animism and dynamism. Life as farmers automatically makes the frequency of their involvement with water high. Water is the main factor for farmers to produce rice which is the staple food of the Javanese. Their religious life also, of course, influences their view of the world. The following discusses the conceptualization of water for the Javanese community as seen through one of the Javanese language products, namely proverbs, based on conceptual metaphors.

\subsubsection{Siblings is Water}

This concept or metaphor is contained in data (1) and (2). In data (1), the sibling relationship is analogous to water. The banyu pinarang proverb means that brotherly relations are not broken. The concept of family brotherhood in Javanese culture can never be broken because of the similarity of 'blood' that flows in the body that comes from their parents. There are no conditions that can change it. The proverb is analogous to the movement of water flowing from top to bottom, which is always unbroken even though a sharp knife cuts it. Then in data 
(2), the tunggal banyu proverb means brother or sister. This analogy is based on the fact that a Javanese family usually has one water source, namely a well, which is used for eating and drinking.

The mapping of siblings that corresponds to water emerges from the experience or learning of the Javanese people when they see the (repeating) phenomenon of water. Sibling relationships are abstract relationships that are difficult to understand, especially when explaining them to children. This abstract concept of brotherhood is then perceived and mapped into a concrete concept, namely water. The correspondence between siblings or kinship relations with water results from their experience of interaction with water and is based on water features. The image schema is water as a fluidity entity. So it can be described that the emergence of the conceptualization of Siblings is Water is an experience of the reality of water based on its nature and existence, which is then perceived by the senses, mapped by cognition, and expressed through language.

\subsubsection{Human Nature is Water}

This This concept or metaphor is found in data (3) and (4). In these two data, human characteristics are correlated with the nature and behavior (movement) of water. For example, in data (3), the proverb Kaya banyu karo lengo means a relationship that does not get along, constantly contradicts. This proverb is motivated by the fact that water and oil will not mix because of specific gravity differences, even though both are liquids. The reality of the relationship between the two liquids is then analogous to the relationship between two people who constantly fight and do not get along. This type of metaphor is a structural metaphor that maps the structure of water and oil into a more abstract structure of human relations. The image schema is human nature which is perceived as an entity like water.

Then in data (4), the proverb Ora ana banyu mili mandhuwur means Human nature is passed down from parents. Parents play a significant role in shaping the character of the child. The data proverb (4) metaphor is an ontological metaphor with a source-path-target orientation image schema; water always flows from top to bottom. Parents pass down a character or human nature to their children.

The metaphor of Human Nature is that Water is formed from mapping the source domain, namely water, into a more abstract target domain, namely human nature. The basis of the mapping is the similarity between water and human nature. Thus, the image schema of the metaphor is water as fluidity existence and source-path-target, particularly the existence of water that cannot mix with oil and always moves down from a higher place to a lower place.

\subsubsection{Community is Water}

The The image schema of water in data (5) and (6) is water as a container. In data (5), water becomes the container in which the needle sinks. When the needle has entered the water, the needle becomes invisible. This is one of the characteristics of the container concept, namely that there is a boundary between the outside and the inside of the container. The meaning of the proverb Edom sumurup ing Banyu is a person who disguises himself. Due to disguise, he became unknown about his true identity. In this proverb, water is analogous to the community. When a person goes undercover in a community, his existence will disappear like the loss of a needle sinks into the water.

Then in data (6), the proverb of Kena iwake ora buthek banyune means that if someone catches criminals, do not panic the whole community. Here the image schema of the water is the container for the fish. Fish become one of the elements in the water with other elements such as fish or other aquatic animals, moss, gravel, mud, and others. Therefore, in the data proverb (6), it is recommended that when catching fish, there is no need to mess with the 
water to make the water dirty or cloudy and disturb the ecosystem in the water. Realities like this are then brought into human reality. When trying to catch a criminal, there is no need to disturb all members of society or damage the peace of society.

The metaphor formed from the image schema of water as a container is a Community is Water. Thus, water is considered a community that becomes a place for the people living in it.

\subsubsection{Sustenance/Valuables is Water}

The Sustenance/Valuables is Water metaphor is formed from the image schema of water as a high-value object or commodity. We know that in rural areas, which generally make a living as farmers, water is an object that is very much needed, both for the necessities of life (eating, drinking, or washing) and for work (irrigating the fields or fields). The absence of water will significantly disrupt the survival of rural residents. During the dry season, crop failures often occur because the rice fields lack water. Realities like this make the Javanese people regard water as a precious commodity.

In data (7), the proverb Kaedusan banyu sasiwur has the meaning of gaining insufficient sustenance. Adus means bathing, which is the activity of cleaning the body by pouring water on the body. Bathing is a Javanese habit that is generally done twice a day, in the morning and evening. The Javanese bathing is an activity related to cleanliness or holiness and can only be done with water. In the morning, bathing is done before doing the main activity, for fathers before work, children before going to school, and mothers before doing household chores. Then in the afternoon, bathing is done to clean the body after being dirty due to the work activities carried out that day. Here, we can see that bathing is an essential routine activity for the Javanese. So when there is no water available for bathing, life is disrupted because it cannot cleanse the body. Realities like this make the Javanese consider water as a valuable entity for their life.

Then in data (8), the proverb Dadia banyu emo nyawuk is usually spoken by angry or hate someone. Because of his/her hate, he/she claims that he/she will never take or use it even if the person he/she hates becomes water. Here the image schema of water is also a valuable commodity or item. In a modern society like today, perhaps the value of water can be equated with money or high-value gems.

\subsubsection{Knowledge is Water}

Geertz [15], in his research, mentions that the Javanese are religious people. It is customary for the Javanese that when they are young, they will study. In general, they study at a boarding school for Muslims and nyantrik or study with someone in a hermitage or college for Javanese adherents. The science studied is the science of religion, life, or kanuragan (martial art). Javanese people firmly believe that science is beneficial for life. This fact is what underlies the formation of the Knowledge is Water metaphor. The image schema of the Knowledge is Water metaphor is Water is Entity. Water as an entity is mapped into abstract knowledge. Abstract science is analogous to concrete water. The basis of mapping is the similarity of the nature of water and science. Good knowledge will benefit humans, just as clean water is also beneficial for the human body.

Conversely, the knowledge that is not good will not be helpful and even damage humans and dirty water that is not good for human consumption. Knowledge is said to be valid if it is taught to others, not only for oneself. Likewise, with water, it will be helpful if it is used, not just stored.

Data (9), namely the proverb Ngangsu banyu ing kranjang, is used as advice that people who seek knowledge, after knowledge is obtained, should be immediately used and taught to 
others. Knowledge should not be kept like water, which should be stored in a container without being used.

\section{Conclusion}

By presenting nine proverb data analyzed with conceptual metaphors, we have described how Javanese make proverbs based on their interactions with the realities they encounter. The experience of Javanese people interacting with water forms an image schema of water as an entity and a container that becomes the source domain for mapping water into various target domains, i.e., siblings, human nature, community, sustenance/valuable things, and knowledge. The basis of mapping is an analogy or similarity to the prototypical features of water resulting from people's experience and interaction with water. It can be concluded that the pattern of proverb formation follows the pattern of reality - cognition - proverbs as language expression. From a proverb containing the word water, we could find that water, according to the Javanese, is seen as a conceptualization of ideological values used as guidelines in social behavior and social relationships.

\section{References}

1. Lakoff, G. \& Johnson, M. Metaphors We Live by. (The University of Chicago Press, 1980).

2. Seitel, P. I. Proverbs and the Structure of Metaphor among the Haya of Tanzania. (1972).

3. Mieder, W. Proverbs are never out of season: Popular Wisdom in the Modern Age. (Oxford University Press, 1993).

4. Norrick, N. R. Subject area, terminology, proverb definitions, proverb features. In Introduction to paremiology: A comprehensive guide to proverb studies (eds. HrisztovaGotthardt, H. \& Varga, M. A.) 8-27 (De Gruyter Open, 2014).

5. Finnegan, R. Oral Literature in Africa. (Oxford University Press, 1970).

6. Strang, V. The Meaning of Water. (Berg, 2004).

7. Noviana, F. Semiotic Study of Japanese Views on Sea in Hayao Miyazaki's Ponyo on the Cliff by the Sea. in E3S Web of Conferences ICENIS 1-4 (2020). doi:10.1051/e3sconf/202020207038.

8. A World of Water: Rain, Rivers and Seas in Southeast Asian Histories. (KITLV Press, 2007).

9. Abe, N. Water and Words: The Difference in the Fluid Metaphor. (2019).

10. Naicker, S. A cognitive linguistic exploration of metaphors within the WATER frame in Swami Vivekananda's Complete Works: A corpus-driven study in light of conceptual metaphor theory. Stellenbosch Pap. Linguist. 47, 115-132 (2017).

11. Ma, Y. \& Suhardi. Entity Metaphors About Water in Cerita Rakyat Jawa Timur. 461, 275-278 (2020).

12. Darmasoetjipta, F. S. Kamus Peribahasa Jawa. (Kanisius, 1992).

13. Kovecses, Z. Metaphor in Culture: Universality and Variation. Vol. 48 (Cambridge University Press, 2005).

14. Saifudin, A. Konseptualisasi Citra Hara 'Perut' dalam Idiom Bahasa Jepang. Japanese Res. Linguist. Lit. Cult. 1, 65-78 (2018).

15. Geertz, C. The Religion of Java. (The University of Chicago Press, 1976). 